Dossier: Poesía, armonía y conflictos: ayer y hoy

\title{
Santo António militar no contexto ibérico
}

Isabel Mํㅡㄹ Dâmaso de Azevedo Vaz dos Santos Faculdade de Letras da Universidade de Lisboa, Portugal

isabel.santos@campus.ul.pt

https://orcid.org/: 0000-0002-2891-3288

Recibido: 1 de agosto de 2019

Aceptado: 20 de setiembre de 2019

Resumo: Uma das vertentes do culto antoniano, de origem puramente portuguesa, reside no facto de se atribuir a Santo António um papel de relevo no campo militar, enquanto protector do exército português. A partir de meados do século XVII, deu-se início a esta tradição, que, com o apoio da monarquia e das instâncias militares, levou a que Santo António fosse alistado no exército português, no seio do qual se distinguiu, nomeadamente nas lutas contra castelhanos e franceses. As prestigiantes patentes e insígnias militares que the foram sendo outorgadas traduzem o êxito das acções militares em que se viu envolvido, contribuindo determinantemente para a defesa da soberania nacional. A partir do século XVIII, são conhecidos vestígios da faceta militar de Santo António posta ao serviço da coroa espanhola, sobretudo nas lutas contra mouros e franceses, assumindo-se igualmente como figura de relevo no processo de garantia da soberania.

Palavras-chave: Santo António; militar; Portugal; Espanha; culto; tradição; imaginário.

\section{Saint Anthony military in the iberian context}

Abstract: One of the aspects of the Antonian cult, of purely portuguese origin, lies in the fact that Saint Anthony is given a prominent role in the military field, as a protector of the portuguese army. From the middle of the 17th century, this tradition began, which, with the support of the monarchy and military institutions, led to Saint Anthony being enlisted in the portuguese army, among which he

\section{(c) (i) (9) (2)}

La Revista Estudios es editada por la Universidad de Costa Rica y se distribuye bajo una Licencia Creative Commons Atribución-NoComercial-CompartirIgual 3.0 Costa Rica. Para más información envíe un mensaje a 
Dossier: Poesía, armonía y conflictos: ayer y hoy

distinguished himself, particularly in the fights against castilians and french. The prestigious military patents and insignia granted to him reflect the success of the military actions in which he was involved, contributing decisively to the defense of national sovereignty. From the 18th century onwards, traces of the military facet of Saint Anthony put at the service of the spanish crown are well known, especially in the fights against moors and french, and also as an important figure in the process of guaranteeing sovereignty.

Keywords: St. Anthony; military; Portugal; Spain; cult; tradition; imaginary

\section{San Antonio militar en el contexto ibérico}

Resumen: Una de las vertientes del culto antoniano, de origen puramente portugués, es el de atribuir a San Antonio un papel importante en el campo militar como protector del ejército portugués. Desde mediados del siglo XVII, que se inició esta tradición, que, con el apoyo de la monarquía y de las autoridades militares, llevó a que San Antonio fuese alistado en el ejército portugués, donde se distinguió, sobre todo en la lucha contra castellanos y franceses. Las prestigiosas patentes e insignias militares que le fueron otorgadas reflejan el éxito de las acciones militares en las que se vio envuelto, contribuyendo decisivamente a la defensa de la soberanía nacional. A partir del siglo XVIII, se conocen vestigios de la faceta militar de San Antonio puesta al servicio de la corona española, sobre todo en las luchas contra moros y franceses, asumiéndose igualmente como figura de relieve en el proceso de garantía de la soberanía.

Palabras clave: San Antonio; militar; Portugal; España; culto; tradición; imaginario.

\section{(C) $(\Theta \odot$}

La Revista Estudios es editada por la Universidad de Costa Rica y se distribuye bajo una Licencia Creative Commons Atribución-NoComercial-CompartirIgual 3.0 Costa Rica. Para más información envíe un mensaje a 


\section{Dossier: Poesía, armonía y conflictos: ayer y hoy}

Uma das vertentes do culto antoniano, de origem puramente portuguesa, reside no facto de se atribuir a Santo António um papel de relevo no campo militar, enquanto protector do exército português. Com efeito, a partir de meados do século XVII, deu-se início a esta tradição, que, com o apoio da monarquia e das instâncias militares, levou a que Santo António fosse alistado no exército português, no seio do qual foi sendo distinguido com sucessivas promoções que Ihe permitiram ascender a diferentes postos, ao longo da sua brilhante e duradoura carreira militar. As prestigiantes patentes e insígnias militares que the foram sendo outorgadas, nem sempre respeitando a sequência hierárquica instituída, traduzem o êxito das acções militares em que se viu envolvido, contribuindo determinantemente para a defesa da soberania nacional.

Segundo o literato Afonso Lopes Vieira, a decisão de fazer ingressar Santo António na carreira militar, apesar de poder ser considerada por algumas pessoas "loucura do tempo ou comédia risível", constitui "um acto admirável de inteligência política e patriótica" (p.13) e contribuiu para muito aumentar e popularizar o seu culto.

Embora haja referência à incorporação de Santo António no exército em 1623, por decisão de Filipe III (Rema, 1998, p. 28), pode-se considerar que a sua carreira militar só se tenha iniciado em 1665, por determinação de D. Afonso VI, quando ordenou que Santo António "fosse alistado no exército, como seu patrono, assentasse praça como soldado e the fosse pago o respectivo soldo" (Ganho, 2001, p. 52). O soldo era geralmente encaminhado para as irmandades de Santo António, até que o Marquês de Pombal decretou a cessação do pagamento e o santo continuou a servir o Exército português mas gratuitamente. No entanto, D. Maria I repôs os pagamentos em 1780.

Santo António assentou primeiramente praça no Terço da Câmara de Lisboa, pouco antes da Batalha de Montes Claros (Matos, 1940, p. 147), facto que encontramos documentado em produções poéticas coetâneas, nomeadamente de 


\section{Dossier: Poesía, armonía y conflictos: ayer y hoy}

Sebastião da Fonseca e Paiva, e de Jerónimo Baía. O primeiro, frade da Ordem de Santiago e mestre da capela da Infanta D. Catarina e do Hospital Real, celebrou este passo da vida militar do santo nas Redondilhas a Santo António alistarse por soldado na occasiam da campanha do Alem-Tejo no anno de 1665:

Se António assentado estais,

Não façais na guerra falha;

E se eis de ir para a batalha

Como assim vos assentais?

Se Portugal vos conduz,

Ide a ser português Marte,

Tendo as armas de uma parte

Tendo de outra parte a Cruz.

Nesse Terço de Lisboa

Desta vez ide alistado;

Que um Terço com tal Soldado

Segurar pode a Coroa.

Bem podeis lançar à quadra

De vossa esquadra o troféu;

Pois das esquadras do Céu

Sois sempre Cabo de esquadra.

Se ser Sargento quereis

Fazei milagroso o dia;

Que em tã boa companhia,
Ajudai-nos, pois, que à fala

Temos o inimigo diante;

Sede pois nosso Ajudante,

Porque o fareis com bengala.

Voai qual ligeira seta,

Meu Capitão singular;

E não deixeis de levar

Vosso pagem de gineta.

Todo o posto vos encampo,

Pois sois soldado de porte;

Que sois Mestre de-Côrte,

Também sois Mestre de Campo.

Ide General perfeito

Eleição que foi dos Céus;

Pois tendes o mesmo Deus

A vossas ordens sujeito.

Ide, que sem quebrar votos,

Sereis um rico soldado;

E posto sois remendado

La Revista Estudios es editada por la Universidad de Costa Rica y se distribuye bajo una Licencia Creative Commons Atribución-NoComercial-Compartirlgual 3.0 Costa Rica. Para más información envíe un mensaje a 
Dossier: Poesía, armonía y conflictos: ayer y hoy

Certo, milagres fareis.

Nunca nós seremos rôtos.

Marchais, Alferes divino, Ide, que postos estão fartos

Para a batalha animoso; De empenhar-nos esta vez;

Pois tremulais vitorioso Tendo nós tal Portuguêz

Por bandeira a Deus Menino.

Faremos Castela em quartos.

Jerónimo Baía, nas Décimas ao Sereníssimo Rey D. Affonso VI quando mandou alistar por soldado ao glorioso Santo António de Lisboa, salientou igualmente o poder milagroso do santo na luta contra os castelhanos, conforme se pode ler:

Alto Rei, fatal excesso

De valentia maior,

Que nisto de ter valor

Sois Rei, que não tendes preço:

Vós, que, com feliz sucesso,

Rompendo as quatro linhas,

Fazeis que as gentes vizinhas,

Quando vem mais insolente,

Não choquem como valentes

Mas choquem como galinhas.

Deixai mais listas, pois já

Santo António se alistou,

Que, como seu pai livrou,

Sua Pátria livrará:

Ele sòmente fará

Com estrago, e com ruina,
Pois que? Com tal valentia

Não vencerá Portugal,

Quando tem soldado tal,

E mais em tal companhia?

Castela de medo fria

Tema tão grande invasão

Que não pode escapar, não,

Empunhando António o braço,

Nem soldado do seu laço,

Nem praça do seu cordão.

Fará cousas nunca ouvidas

Em favor dos Lusitanos,

Não sendo dos castelhanos

Como ser das coisas perdidas:

Tingirá cortando vidas,

De vermelho o burel pardo,

La Revista Estudios es editada por la Universidad de Costa Rica y se distribuye bajo una Licencia Creative Commons Atribución-NoComercial-CompartirIgual 3.0 Costa Rica. Para más información envíe un mensaje a revistaestudios.eeg@ucr.ac.cr. 


\section{Dossier: Poesía, armonía y conflictos: ayer y hoy}
Castela sempre mofina,
E, com ímpeto galhardo,
Pois tem para vencedor
Triunfando em todo o risco,
Como Português valor
Posto que é frade Francisco,
Como Santo disciplina.
Brigará como um Bernardo.

Ele só será bastante

A vencer nosso inimigo;

Porém não só, pois consigo

Traz sempre o melhor Infante:

Já foi do mundo triunfante

Este Infante que conduz,

Fazendo espada da Cruz;

Este pode o que quizer

E quer o que António quer,

Por ser o seu «Ai Jesus».
Com hábito, e fidalguia

Será de Castela açoite,

Se como frade de noite,

Como fidalgo de dia.

Cante a Lusa Monarquia,

Chore a contraria nação,

Pois ambas nele terão,

Para glória e para dor,

Uma nas mangas favor,

Outra nas bragas prisão.

Foi nos confrontos com as tropas espanholas que Santo António começou a destacar-se na protecção do exército português, crendo-se que a presença da sua imagem entre os soldados sob a sua protecção lhes fazia redobrar as forças e a confiança, conduzindo-os à vitória. Santo António, cuja figura emerge como símbolo de identidade nacional, ganha, assim, o estatuto de Patrono do Reino.

Com a Restauração, em 1640, intensificaram-se as homenagens ao santo, considerando-o defensor do reino, capaz de recuperar a soberania perdida. Assim foi interpretado como sinal divino o facto extraordinário de, aquando da procissão organizada a partir da Sé, na manhã do dia 1 de Dezembro de 1640, o braço direito da imagem de Cristo crucificado se ter desprendido da cruz, justamente à porta da Igreja de Santo António, tal como testemunha o sermão de Fr. João da 


\section{Dossier: Poesía, armonía y conflictos: ayer y hoy}

Natividade (Marques, 1989, p.145). Este episódio milagroso, transmitido até sob a forma de lenda (Lendarium, № 734) pretende confirmar o carácter milagroso da Restauração de Portugal.

Após a Restauração, começaram a ser divulgadas as virtudes militares de Santo António e, em reconhecimento pelas vitórias alcançadas, D. Pedro II, ainda na qualidade de regente do reino, ordenou que Santo António assentasse praça como soldado no $2^{\circ}$ Regimento de Infantaria de Lagos, em finais de Janeiro de 1668, tendo como fiadora a Virgem Maria, responsável pelo seu "comportamento" como soldado (Lima, 1939, p. 233). Recorde-se que, à época, era imprescindível que qualquer soldado apresentasse como fiador uma figura cuja idoneidade fosse intocável e reconhecida publicamente. Santo António não poderia ter ingressado na sua carreira militar com melhor fiadora, o que prognosticaria, desde logo, a sua excepcional e exemplar conduta militar.

Note-se que poucos dias depois, a 13 de Fevereiro desse mesmo ano, é firmado o tratado de paz entre os dois países - Tratado de Lisboa -, estabelecido através dos seus monarcas, Afonso VI de Portugal e Carlos II de Espanha, no qual se reconhece a Restauração da Independência de Portugal'.

A imagem de Santo António, protector do Regimento de Lagos, ostentando a banda de oficial e o bastão de comando, encontra-se no Museu Municipal da cidade, anexo à Igreja de Santo António dos Militares, juntamente com o altar de campanha que acompanhou este Regimento ao longo das batalhas (Aguiar, 1952, p. 48).

Em 1683, no dia em que D. Pedro II assumiu o trono, Santo António foi promovido a capitão, na sequência da vitória face ao exército espanhol que se retirou por Olivença, perante a valentia dos militares portugueses (Pinto, 1948, p.31).

Foi realmente nos confrontos com as tropas espanholas que Santo António militar mais se destacou na protecção do exército português. A sua imagem

La Revista Estudios es editada por la Universidad de Costa Rica y se distribuye bajo una Licencia Creative Commons Atribución-NoComercial-Compartirlgual 3.0 Costa Rica. Para más información envíe un mensaje a 


\section{Dossier: Poesía, armonía y conflictos: ayer y hoy}

acompanhou o vitorioso exército português, comandado pelo Marquês de Minas, na sua entrada em Madrid, em 1706.

Ainda por ordem de D. Pedro II, Santo António foi alferes do Regimento de Infantaria nํ 13 de Peniche, sendo também padroeiro desta unidade.

Em 1733, começou a receber o soldo como capitão, no valor de quinze mil réis, conforme carta-régia emitida por D. João V (Lima, 1939, p. 234).

D. Maria I, no início do seu reinado, em 1777, recebeu do Major do Regimento de Lagos uma petição para que Santo António fosse promovido ao posto de major, tendo em conta o seu exemplar desempenho militar, os bons serviços prestados e os muitos milagres operados. Três anos depois ascendia ao posto de oficial-general.

O culto a Santo António militar foi trazido de Lagos e incorporado no Regimento de Infantaria no 19 de Cascais, que passou a fazer-se acompanhar da imagem do santo, combatendo nas Guerras Napoleónicas, designadamente no campo da Batalha do Buçaco. Em 1810, os franceses resolveram fazê-lo prisioneiro, motivo pelo qual os soldados de Cascais levaram a cabo, com sucesso, uma grande ofensiva no lugar de Santo António do Cântaro (Aguiar, 1952, p. 35). Em 1814, D. João VI atribuiu-Ihe a graduação de tenente-coronel de Infantaria, como forma de agradecimento pela paz conseguida com a França. Nesse mesmo ano, foi também agraciado com a Grã-Cruz da Ordem Militar de Cristo. Mesmo assim, só em 1814, assinada a paz com a França, foi recuperada a imagem aprisionada de Santo António, que guarda algumas cicatrizes dos ferimentos sofridos em combate e que foi colocada na ermida de Nossa Senhora da Vitória, no Buçaco, que pertence ao Museu Militar.

Uma cópia fiel desta imagem foi entregue ao Regimento de Cascais (Cunha, 1995, p. 25) e guardada na Cidadela de Cascais, de onde saía anualmente, transportada por uma mula branca e rodeada por militares deste

\section{(c) (i) (-)}

La Revista Estudios es editada por la Universidad de Costa Rica y se distribuye bajo una Licencia Creative Commons Atribución-NoComercial-CompartirIgual 3.0 Costa Rica. Para más información envíe un mensaje a 


\section{Dossier: Poesía, armonía y conflictos: ayer y hoy}

Regimento, para participar na procissão do dia 13 de Junho, feriado municipal desta cidade.

Uma vez que o espaço da Cidadela passou para a posse da Câmara Municipal no início de 2005 e levou outros destinos, o Regimento foi reconduzido para Queluz. Como esta imagem do santo continua a acompanhar os seus militares, foi também deslocada para o Salão Nobre do Regimento de Artilharia Anti-Aérea de Queluz, onde ficou até à reabertura da capela de Nossa Senhora da Vitória no espaço da Cidadela, sujeita a obras de remodelação, onde se encontra desde 2011, a título de empréstimo, e tem sido incorporada na procissão em honra de Nossa Senhora dos Navegantes, integrada nas Festas do Mar e realizada no último domingo de Agosto. A capela, construída após a Restauração em estilo nacional, constitui um elemento simbólico de identidade nacional na medida em que serviu para estimular os artistas portugueses a criar um estilo novo e próprio, por afastamento da influência espanhola.

Santo António assumiu igualmente postos militares no exterior, nomeadamente no Brasil, em Moçambique, em Macau, na Índia.

Por outro lado, são conhecidos alguns vestígios da faceta militar de Santo António postos ao serviço da coroa espanhola, nomeadamente nas lutas contra mouros e franceses.

É atribuída a Santo António colaboração na conquista aos mouros da cidade de Orã (na actual Argélia) por parte do exército espanhol a mando do rei $D$. Felipe V, em 1731. Existe uma lenda que conta que, antes de partir para o norte de África, o oficial responsável pela campanha militar visitou uma capela dedicada a Santo António para pedir auxílio. Em troca da ajuda do santo, o oficial espanhol colocou aos pés do santo o seu chapéu de plumas e uma espada.

Ao chegar a Orã, o exército espanhol deparou-se com um cenário inesperado, pois, ao contrário do que seria de esperar, a população não ofereceu resistência. Quando questionados sobre a situação, os locais contaram que, antes 


\section{Dossier: Poesía, armonía y conflictos: ayer y hoy}

da chegada das forças espanholas, tinha passado por ali um frade com um chapéu de plumas e uma espada que lhes disse que, se tentassem lutar contra os espanhóis, a cidade seria destruída.

Em agradecimento, o monarca terá promovido o santo a almirante, com soldo correspondente pago em forma de esmola ao Convento de San Antonio de Padua, de Alicante, onde se rezou missa em honra do santo antes da partida rumo à vitória da cidade do norte de África.

Ainda em referência à vivência africana de Espanha, veja-se a obra San Antonio a lo militar: romance de dos portentosos milagros que ha obrado el glorioso San Antonio con un devoto y una devota llamado el caballero don Francisco de Hermosilla y Valdepeñas, y la señora doña Tomasa de Castilla y Cerezuela, naturales de la ciudad de Burgos. Declárase cómo el caballero fue cautivo, renegó y se casó con una turca (BNM VE/1360/12), impresso em Córdoba, na Imprenta de Don Rafael García Rodríguez, que operou entre 1805 e 1844.

Na primeira parte, conta-se como Doña Tomasa se sentiu protegida por Santo António quando este, vestido de militar, interveio para impedir que ela fosse violada por Don Francisco, que se pôs em fuga. A segunda parte incide no tópico da viagem atribulada empreendida por Don Francisco, que termina preso e convertido à fé muçulmana. Mais uma vez, Santo António surge para repor a ordem, levando à recuperação da fé cristã e até à conversão da mulher moura com quem Don Francisco se tinha casado, que sente um forte apelo pela religião católica através do poder da imagem de Santo António.

Importa ainda referir o retábulo dos milagres de Santo António da Iglesia de San Francisco da cidade de Lorca, município de Murcia, constitui uma forma de agradecimento pelo auxílio prestado por Santo António. Conta-se que os lorcanos se colocaram sob a protecção de Santo António, facto que resultou na vitória da cidade contra o Marquês de Villena quando, em 1733, este procurava dominar as 


\section{Dossier: Poesía, armonía y conflictos: ayer y hoy}

localidades de Xiquena y Tirieza, bem como o regadio procedente do rio Vélez (Segado, 1996, p. 1277). Julga-se que o remate do retábulo, conseguido com a figura do arcanjo São Miguel, capitão das hostes celestiais, está relacionado com este episódio, em que Santo António se revelou, uma vez mais, protector da independência e da identidade dos povos.

$\mathrm{Na}$ abóbada da capela de Santo António da igreja do Convento de San Francisco em Palma de Mallorca, encontra-se uma pintura que representa o santo vestido de franciscano mas com um chapéu de inspiração militar. Nas paredes encontram-se outras pinturas que relatam episódios conhecidos da vida e da taumaturgia do santo. De acordo com o que consegui apurarii, através de Frei Arturo Plaza, a capela, dedicada anteriormente a Santa Madalena e a São Roque, passou para a advocação de Santo António em 1744, quando foi restaurada e terá sido dotada destas pinturas, provavelmente da autoria do pintor maiorquino Guillem Mesquida i Munar que, falecido em 1747, aí se encontra sepultado (Tous, 1982, p. 503). Quanto às circunstâncias que terão determinado a natureza desta pintura do tecto, consta que constitui um agradecimento que o capitão de uma embarcação quis gravar pelo socorro que recebeu de Santo António, quando se encomendou à sua protecção no momento em que corria sério perigo de naufrágio provocado pelo ataque de uma embarcação inimiga.

Em 1762, colocada a imagem de Santo António no cimo das muralhas, auxiliou na defesa de Almeida contra as tropas espanholas e francesas, pelo que uma das suas portas e um dos baluartes da fortaleza conservam o seu nome (Aguiar, 1952, p.26). Note-se que a praça de Almeida ocupava um lugar de grande importância estratégica na defesa do território português face à forte praça espanhola de Ciudad Rodrigo (Borges, 2011, p. 631).

Pelos mesmos motivos, e entre outros exemplos, encontramos sob a invocação de Santo António diversas equipamentos do complexo de fortificações nacionais: portas nos castelos de Bragança, Mirandela, Monsanto e Estremoz;

La Revista Estudios es editada por la Universidad de Costa Rica y se distribuye bajo una Licencia Creative Commons Atribución-NoComercial-CompartirIgual 3.0 Costa Rica. Para más información envíe un mensaje a 


\section{Dossier: Poesía, armonía y conflictos: ayer y hoy}

baluartes na praça-forte de Valença, de Caminha e em Setúbal; torres em Cascais e em Avis; fortes no Estoril, em Évora e em Beliche.

Com efeito, Santo António é invocado em grande parte das fortalezas militares construídas para defesa nacional após o período de recuperação da soberania, como homenagem pelos feitos conseguidos e como garante de independência e de soberania nacionais.

Também em Espanha, existem alguns cabos de San Antonio, como por exemplo na costa valenciana (Alicante) ou na costa das Asturias (Llanes), que contam também com ermidas dedicadas ao santo.

Como verificamos, nem sempre é possível encontrar uma coerência hierárquica na progressão de Santo António na carreira militar. Contudo, um dos aspectos mais curiosos de que se reveste a tradição militar em torno da sua figura é o facto de lhe terem sido prestadas honras em territórios que ultrapassam os limites de Portugal e das suas ex-colónias, conforme se verifica, por exemplo, em Alicante (Espanha), em Nápoles (Itália), na Baviera (Alemanha), na região do Tirol, entre outros. Santo António esteve ainda alistado no exército inglês, na sequência da Guerra Peninsular.

Ainda em finais do século XIX, aquando das comemorações do VII Centenário do nascimento de Santo António, surgiu a ideia de proceder à sua promoção a coronel, o que não chegou a acontecer. Por ocasião das referidas comemorações, foi também dirigida ao Governo uma petição, solicitando que Santo António fosse declarado Padroeiro do Exército Português, em substituição de São Jorge, tendo em conta o valor dos actos prestados ao longo da sua carreira militar e o facto de simbolizar a grandeza da identidade nacional, sugestão que foi retomada em 1931, quando se assinalou o VIIo Centenário da sua morte (Aguiar, 1952, p. 43).

A 13 de Junho de 1934, o Papa Pio XII designou Santo António como Protector de Portugal, juntamente ${ }^{\mathrm{iii}}$ com a Imaculada Conceição ${ }^{\mathrm{iv}}$. Pode-se 


\section{Dossier: Poesía, armonía y conflictos: ayer y hoy}

considerar que esta consagração culminou o processo de transformação de Santo António em símbolo nacional enquanto emblema iconográfico da soberania e da identidade portuguesas.

Em suma, note-se que a carreira militar de Santo António começou cerca de 400 anos após a sua morte, em meados do século XVII. Quer na guerra quer na paz, Santo António sempre foi uma fonte de consolo e de força para aqueles que o procuravam.

A faceta militar de Santo António encontra-se também inscrita em faiança de cerâmica decorativa exposta no Museu de Santo António:

Santo António assentou praça Sant'António é bom santo

Foi El-Rei que assim mandou

Que livrou seu pai d'arganos

É soldado como a gente

Também nos há-de livrar

Co'a gente na guerra andou.

Do poder dos castelhanos.

Notas

'Nesta sequência, foram devolvidos a Portugal prisioneiros e territórios, excepto Ceuta, que ficaria para sempre na posse de Espanha.

ii Através de Frei Arturo Plaza, a quem agradeço a cordialidade com que me recebeu no convento e todas as diligências que empreendeu para dar resposta aos meus insistentes telefonemas com pedidos de informação sobretudo acerca da curiosa pintura a fresco da abóbada da capela de Santo António.

iii "Santo António, protector de Portugal", in Diário da Manhã, 14 de Junho de 1934, p. 1.

v Recorde-se que já D. Afonso Henriques colocara o reino sob a protecção de Nossa Senhora mas foi D. João IV, em 1646, quem decretou tomar por "Padroeira dos Nossos Reinos e Senhorios a Santíssima Virgem Nossa Senhora da Conceição". Cf. Alfredo Ferreira do NASCIMENTO, Santo António de Lisboa, no 6 da Colecção "História de Portugal", Lisboa, Empresa Nacional de Publicidade, 1963, p. 102.

\section{(c) (i) (9) (2)}

La Revista Estudios es editada por la Universidad de Costa Rica y se distribuye bajo una Licencia Creative Commons Atribución-NoComercial-CompartirIgual 3.0 Costa Rica. Para más información envíe un mensaje a revistaestudios.eeg@ucr.ac.cr. 
Bibliografia

Aguiar, J. P. (1952). Santo António de Lisboa: Oficial do Exército e Herói Nacional. Lisboa: Sociedade Astória.

Baía, J. (1665). Décimas ao Sereníssimo Rey D. Affonso VI quando mandou alistar por soldado ao glorioso Santo António de Lisboa. Lisboa: Off. de Henrique Valente de Oliveira.

Borges, A. M. (2011). Toponímia dos edifícios religiosos. En AA.VV., O Esplendor da austeridade. Mil anos de Empreendedorismo das Ordens e Congregações em Portugal: Arte, Cultura e Solidariedade (pp. 631-632.). Lisboa: Imprensa nacional Casa da Moeda.

Cunha, V. (1995). Santo António. Doutor da Igreja e Oficial do Exército. Comemorações do 8ํㅡㄹ Centenário do seu Nascimento. En Jornal do Exército (pp. 21-25). Lisboa: Estado-Maior do Exército.

Ganho, M. de L. S. (2001). O essencial sobre Santo António de Lisboa. Lisboa: Imprensa Nacional-Casa da Moeda.

Lima, H. C. F. (1939). Santo António Militar. Boletim do Arquivo Histórico Militar, Vol. IX, 229-243. Lisboa: Arquivo Histórico Militar.

Marques, J. F. (1989). A apologia do santo natural: S. António, advogado da recuperação política de Portugal e seu activo defensor na contenda com Castela. En A Parenética Portuguesa e a Restauração 1640-1668 (Vol. 1., pp. 145-149). Porto: Instituto Nacional de Investigação Científica-Centro de História da Universidade do Porto.

Matos, G. M. (1940). Notas sobre Santo António Militar. En Boletim do Arquivo Histórico Militar (Vol. X, 151-168). Lisboa: Arquivo Histórico Militar.

\section{(c) (i) (3) (2)}

La Revista Estudios es editada por la Universidad de Costa Rica y se distribuye bajo una Licencia Creative Commons Atribución-NoComercial-CompartirIgual 3.0 Costa Rica. Para más información envíe un mensaje a revistaestudios.eeg@ucr.ac.cr. 
Paiva, S. F. (1665). Redondilhas a Santo António alistarse por soldado na occasiam da campanha do Alem-Tejo no anno de 1665. Lisboa: off. De Henrique Valente de Oliveira.

Pinto, J. E. (1948). Santo António de Lisboa. Grandes Portugueses. Lisboa: Edições SNI.

Rema, H. P. (1998). A piedade popular e Santo António. Cultura, 28, nota 32.

Segado, P. (1996). Los milagros de San Antonio en la retablística de Lorca (Murcia). En A.VV., Actas do Congresso Internacional Pensamento e Testemunho: $8^{\circ}$ Centenário do Nascimento de Santo António (Vol. II, 1275-1296). Braga: Universidade Católica Portuguesa e Família Franciscana Portuguesa.

Tous, J. J. (1982). Guillem Mesquida i Munar, el gran pintor mallorquí. En Guillem Mesquida, pintor mallorquí (pp. 502-507). Palma de Mallorca: Ajuntament de Palma.

Vieira, A. L. (1932). Santo António - Jornada do Centenário. Lisboa: Imprensa Nacional. $\quad$ http://www.lendarium.org/narrative/lenda-do-braco-direitoestendido/?tag=734. 